\title{
RESEARCH AND DEVELOPMENT IN BRITISH COLONIES, 1950-5I
}

$\mathrm{T}$ O those annual reports of research and development in British Colonies which were last year collected under the title "Colonial Research" there have now been added reports for $1950-51$ from the Tsetse Fly and Trypanosomiasis Committee, the Colonial Fisheries Advisory Committee and the Director of the Anti-Locust Research Centre. The present omnibus volume covering 1950-51* thus includes, besides these three reports, the annual report of the Colonial Research Council, the eighth annual report of the Colonial Products Research Council, the seventh annual report of the Colonial Social Science Research Council, the sixth annual reports of the Colonial Medical Research Committee and of the Committee for Colonial Agricultural, Animal Health and Forestry Research, and the fourth annual reports of the Colonial Insecticides, Fungicides and Herbicides Committee and of the Colonial Economic Research Committee. The broad background against which all this work is carried out and a general picture of the work itself is contained in the earlier report, "The Colonial Territories (1950-51)" (see Nature, October 20, p. 691). The present report gives the fuller details which the scientific worker expects, together with the particulars of membership of the several councils and committees and lists of publications.

Appended to the report of the Colonial Research Council is a list of research schemes-including fiftyseven now schemes and some sixty supplementary ones made during the year-and of the grants allotted from Colonial Development and Welfare funds. The total of $£ 2 \frac{1}{2}$ millions is the highest annual figure recorded, and brings the grant for research schemes since 1940 to about $£ 10 \frac{1}{4}$ millions. After deductions for unspent balances, etc., the net expenditure and commitment on March 31,1951 , was about $£ 9 \cdot 6$ millions, of which slightly more than $£ 9.3$ millions is chargeable against funds provided by the 1945 and 1950 Acts, and to this must be added some $£ 2$ millions provided by Colonial governments or industry. The actual disbursement of $£ 1,406,651$ during the year is the highest recorded, and indicates that major schemes which have been hampered in their progress by scarcity of scientific personnel, labour, building material and equipment are now getting well under way. About $31 \cdot 5$ per cent of the gross allocation has been for agricultural, animal health and forestry schemes, 14.4 per cent for fisheries research, $13 \cdot 7$ per cent for medical research, $11 \cdot 9$ per cent for tsetse and trypanosomiasis research, 8.4 per cent for social science and economic research, $6 \cdot 3$ per cent for insecticides research, 4.6 per cent for research sponsored by the Colonial Products Research Council, 3.3 per cent for anti-locust research and 5.9 per cent for miscellaneous schemes. Major schemes approved during the year were $£ 150,000$ for the establishment of the West African Trypanosomiasis Institute and its maintenance for five years ; a further $£ 134,745$ for the West African Fisheries

* Colonial office. Colonial Research 1950-51: Reports of the Colonial Research Council Colonial Products Research Council Colonial Social Science Research Council Colonial Medical Research Council, Committee for Colonial Agricultural, Animal Health and Forestry Research, Colonial Insecticides, Fungicides and Herbicides Committee, Colonial Economic Research Committee, Tsetse Fly and Trypanosomiasis Research Committee, Colonial Fisheries Advisory Committee, Director, Anti-Locust Research Centre. (Cmd. 8303.) Pp. 243. (London: H.M. Stationery Office, 1951.) 6s. $6 d$. net.
Research Institute ; $£ 135,000$ capital expenditure for the establishment of the East African Medical Survey and Filariasis Research Unit; $£ 126,048$ for the East African Institute of Social Research for five years; $£ 200,000$ for the maintenance for five years of the East African Tsetse and Trypanosomiasis Research and Re. clamation Organization; $£ 280,000$ for the establishment and maintenance for five years of the East African Central Trypanosomiasis Research Institute; $£ 263,000$ for the East African Veterinary Research Organization; $£ 217,228$ for the promotion of agricultural research in Northern Rhodesia; and $£ 260,000$ for the establishment of a Marine Fisheries Research Station in Singapore.

Commitments against the $£ 13$ millions for Colonial research schemes allotted from the additional funds made available by the 1950 Colonial Development and Welfare Act reached approximately $£ 8 \cdot 3$ millions by the middle of 1950, and in December 1950 the Colonial Research Council recommended that the balance should be apportioned between the various fields of research as follows : general reserve, $£ 425,000$; agriculture, animal health and forestry research,

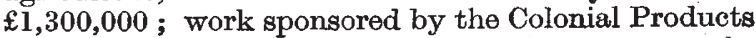
Research Council, £200,000; anti-locust research, $£ 100,000$; insecticides (including fungicides and herbicides) research, $£ 550,000$; tsetse and trypanosomiasis research, $£ 425,000$; fisheries research, $£ 475,000$; medical research, $£ 600,000$; social science research, £325,000; economic research, $£ 100,000$; and miscellaneous research (including industrial and engineering), $£ 200,000$. The Council also endorsed a proposal of the Colonial Office. that the various research committees and councils should be asked to make recommendations as to the most profitable use of their funds apportioned to their respective fields to meet all new money required during the next five years, including provision for the research of important schemes.

The Scientific Council for Africa South of the Sahara has now been duly established, with Dr. P. J. du Toit as chairman and Dr. E. B. Worthington as secretary-general, and held its first meeting at Nairobi during November 1950. During the year an American hydrologist and engineer were engaged to survey flood conditions on the Kafue Flats in Northern Rhodesia, and a malacologist was secured to investigate the schistosome-transmitting snails in West Africa. A fourth scientific worker has been assisting in locust research at Cambridge. A further survey was made by the African Studies Branch of the Colonial Office of racial differentiation in the laws of all the African territories, and arrangements have been made for the reproduction of a bibliography of published sources relating to land tenure in the South-East Asia and Pacific Colonial territories compiled by the Colonial Land Tenure Advisory Panel. The report of the Colonial Building Research Liaison Officer on his visit to Africa in the autumn of 1949 has been endorsed generally by the Council. The report emphasized the need for encouraging the better use and improved manufacture of local materials and more economical building design. Problems which require urgent study include the behaviour of materials in tropical climates, the development of material manufactures and methods of construction suitable for African conditions, the 
design of buildings for comfort in hot climates, and low-cost housing for the African urban population. Research is also needed into the penetration of moisture through building materials and the fortification of native materials to resist insect and mould attack. A manual relating to the protection of buildings and timber against termites has been published. A census was held in Bermuda during October, and in Lagos in February, 1950. Recruitment of staff for the Directorate of Colonial (Geodetic and Topographic) Surveys made progress, and field survey work was maintained mainly in Africa, where the Royal Air Force continued air-photography in East, Central and West Africa. Mapping increased and considerable progress was made in the investigation of mineral deposits. Some fifty-two additional geologists, geophysicists and chemists were appointed during the year, and the universities are now being asked to extend their interest in Colonial geological research. In meteorology the principal development has been the progress towards a West Indies Meteorological Service, covering the West Indian Colonies and the Bahamas, with its headquarters in Trinidad (see also Nature of November 3, p. 769) ; but progress has also been made in the programme of radiosonde/ radar wind stations and the facilities they will provide for the study of upper-wind conditions. The Colonial Road Research Liaison Officer visited Kenya, Uganda, Tanganyika and Zanzibar during September-October 1950. A report on this visit will shortly be issued. This visit has led to the conclusions, among others, that the more technical road problems of East Africa are broadly similar to those of West Africa, but are aggravated by the greater prevalence of poor-quality soils and roadstones, and that research on Colonial soils and roadstones, and indigenous materials such as karkar, coral, soda, wood-tar, and agricultural wastes, and to determine the minimum thickness and quality of road suitable for Colonial conditions, is urgently needed.

The report of the Colonial Products Research Council again consists of a general part and a more detailed review of some research work in progress. Much attention has been given to the fermentation of the cocoa bean, and it has been established that the predominant species of yeast in cocoa beans commercially fermented in Trinidad and Grenada is Candida krusei (A. Cast.) and that Saccharomyces species never represent a significant percentage of the total yeast microflora. The observation that the chocolate flavour develops after drying and roasting if aseptic ripe pods are left for some days in dilute solutions of either acetic acid or sodium acetate (but not citric or phosphoric acid) at $48^{\circ} \mathrm{C}$. may prove of immediate industrial value. Work on the antibiotic 'comirin' is continuing, particularly with the viow of utilizing it as a fungicide or in the protection of paper, canvas and paints. The Colonial Microbiological Research Institute has also investigated the red root disease of West Indian limes and the artificial cultivation of the edible mushroom, Volvaria esculenta, Bresadola, and at the University College of the West Indies Prof. C. H. Hassall and Miss L. Wong have shown that the antibiotic, monamycin, separated from a strain of Meredith's actinomycete, is not identical with musarin.

In the work at the University of Birmingham under Prof. M. Stacey more attention has been directed to the action of bacteria on sugar and other carbohydrates. Prof. Stacey's observation that ultrasonic sound waves can degrade the highly polymeric dextran obtained by the action of bacteria on sugar to give the blood plasma substitute previously prepared by acid hydrolysis has been applied in a completely new manufacturing process for this substance. The structures of various ethylidene derivatives of $d$-mannitol have been elucidated by G. T. Bruce, and a series of trifluoroacetyl derivatives of amino-sugars possessing unusual properties prepared by Dr. C. M. Tatlow are being further investigated. A detailed study of sugar-cane wax isolated from the filter muds of all the sugar estates in the West Indies is being made in collaboration with Prof. L. F. Wiggins, of the Imperial College of Tropical Agriculture, Trinidad, and a method for the purification of the wax is being tried on a pilot-plant scale, as is a method for the manufacture of lactic acid. A high grade of cellulose has been obtained by Prof. Stacey by the action of bacteria on sugar, molasses and effluents containing sugar. The examination of the pharmacological action on the nervous system of sugar derivatives prepared by Prof. Wiggins and his collaborators indicates that, with one exception, the seventy pyridazone derivatives screened are unlikely to be suitable for clinical trial. In Prof. Stanley Peat's laboratory at the University College of North Wales, Bangor, the complex system of enzymes involved in the metabolism of starch in the higher plants has been further studied.

Considerable progress has been made in the study of the thermal polymerization of drying oils, and the study of the component glycerides in Stillingia oil has been completed, as well as some further studies on deca-2 : 4-dienoic acid and its derivatives. Trials in different areas in Australia have demonstrated the marked effect of climatic conditions on sunflower seed oils, and sufficient information has now been obtained from the experimental plots to justify the Director of Agriculture, Nigeria, starting the cultivation on an area of two hundred acres of the vine, Tetracarpidium conophorum, the oilseeds from which provide the conophor oil in which the paint industry is interested; but although the prototype machine for decorticating candlenuts (Aleurites triloba) gives a satisfactory separation of shells and kernels, the latter are damaged to an extent which renders them unsuitable for export. Work has continued on plants of possible medicinal and insecticidal value : a study of the essential oil from the wood of Brachylaena hutchinsii has been completed, and the structure of the phenol, ehlorophorin, present in Chlorophora excelsa wood established. Experiments on the purification of the germination factor for Striga hermonthica have been actively pursued at the Universities of Leeds and Cambridge. Examination of samples of the oleo-resin from Pinus cariboea (British Honduras) have shown that the oil of turpentine and resin are of excellent quality.

The seventh annual report of the Colonial Social Science Research Council estimates that a little more than $£ 100,000$ remains available for the next five years for new projects and contingencies in this field. While recruitment of junior research staff improved, difficulty is still being experienced in recruiting sociologists qualified to undertake field demographic studies and urban surveys, and senior men for appointments of two or more years. Special efforts have been made to associate the staff of university colleges in the Colonies with the work of the institutes of social and economic research. Besides the organization by University College, London, of anthropological investigations in the Jos 
Plateau and Cross River areas, the two studies of the social structure of an Indian community in Fiji and of the development of social welfare services in Tonga (sponsored by the Research School of Pacific Studies of the Australian National University) and the social science research financed by the University of Malaya and the University College of the Gold Coast, some social science projects have been sponsored by Colonial governments without assistance from Colonial Development and Welfare funds. Research into the grammar and structure of the Somali language, for example, has been carried out by the Director of Education, Somaliland Protectorate; the Tanganyika Government has employed three sociologists, who were to investigate land usage and associated problems in the highland areas of the Northern Province, make a two-year intensive study of the Sukuma tribe, and also a study of the Makere tribe of the Southern Province. The Government of the Gold Coast has financed further research into the teaching of English and into customary land tenure in the northern territories, while the Institute for Medical Research, Malaya, has made studies into the social and economic factors in food consumption, in conjunction with clinical and dietary investigations into malnutrition. The Ethnographic Survey of Africa by the International African Institute has made considerable progress; the survey of the Northern Bantu linguistic border was nearing completion and two sections of the survey of the languages of Africa (Berber languages of North Africa and languages of West Africa) were in the press. Besides brief notes on various socio-economic, ethnographic and anthropological studies in progress in Africa, in SouthEast Asia and the Pacific and the Caribbean, including also some investigations on psychological testing, the report includes as appendixes reports on work of the Institute of Social and Economic Research of the University College of the West Indies, the West African Institute of Social and Economic Research, which began operations in October 1950, the East African Institute of Social Research, which started work in May 1950, and the Rhodes-Livingstone Institute; appendixes also deal with research under the auspices of the University of Malaya and with research in social sciences at the University College of the Gold Coast and in education at Singapore. The policy and proposed programme of research of the West African Institute are given in full.

All the main schemes under the Colonial Medical Research Committee continued during 1950-51; but the sixth annual report again records inadequate recruitment. Only $£ 600,000$ was available from Colonial Development and Welfare funds for continuance of these and for the initiation of new schemes up to 1956, and the programme is under review in the light of this allocation. The Filariasis Research Unit established at Mwanza, Tanganyika, has now been fully staffed and has extended its surveys of filarial infections in the area. Studies on the chemotherapy of bancroftian filariasis have confirmed the high tolerance of the African for doses of the piperazine derivative, 'Hetrazan'. Investigations on loiasis in the Cameroons continued, and in southwest Nigeria a study of the ecology of the local species of Cyclops (the copepod crustaceans dwelling in ponds and streams which serve as intermediate hosts to the guinea worm) and a survey of the infection in the area have been commenced. Reasonably good results were obtained in the first twelve months of an experiment in the control of malaria in four valleys in Negri Sembilan, Malaya, in which all houses in one valley were sprayed with DDT, in another with 'Gammexane', while in a third proguanil was distributed weekly to the population. Studies of the effectiveness of DDT and 'Gammexane' against Malayan mosquitoes have also been made, while in North Borneo, besides studies of the repellent effect of DDT to A. leucosphyrus, the entomological, spleen and parasite surveys required for the Tambunan experiment to determine whether malaria can be controlled by the localized clearing of jungle growing over $A$. leucosphyrus breeding places has continued. Malaria research in Jamaica has been directed chiefly to the study of the habits and infectivity of suspected malaria vectors, mainly Anopheles albimanus, and the distribution of anopheline bites among different human age-groups in relation to general problems of melaria transmission and epidemiology ; in Trinidad investigations on outside-resting $A$. aquasalis were intensified, and others on the relative attraction of various animals for aquasalis, night activity and ecological studies of various types of breeding places were started. An investigation of the natural history of malaria in African infants in Nigeria was concluded, and comparative field trials on three groups of 245 African school-children naturally infected with $P$. falciparum, $P$. malarice and $P$. ovale showed that all malario-metrical indices decreased more rapidly in the chloroquine than in either the mepacrine or the proguanil groups.

Neither a director nor adequate scientific staff have yet been secured for the West African Virus Research Institute, Lagos, but at the East African. Virus Research Institute, Entebbe, Uganda, a longterm programme of research on rickettsioses, with special emphasis on tick-typhus, has been commenced and research on the epidemiology of yellow fever has continued. Further work on the preparation of specific precipitin sera for the identification of bloodmeals of insects was carried out at the Lister Institute, London, and the scrub-typhus field research unit of the Institute for Medical Research, Malaya, has completed a general survey of potential mammalian hosts and trombiculid mites, which has shown that the common giant rats ( $R$. sabanus, $R$. mülleri) of the Malayan forest are the proper hosts of the vectorspecies group of mites, while the stream- and gulleyinfesting species $R$. müllerei is the chief host of Trombicula deliensis itself in the forest." The Field Research Station, Fajara, Gambia, is now better placed to conduct its investigations into causes of ill-health and inefficiency among the rural African population and on measures likely to alleviate or eradicate them. In Malaya clinical trials of thiacetazone against leprosy are well advanced, and in Nigeria, following a study and assessment of the value of sulphone treatment, an attempt is being made to develop a simple, cheap and effective form of sulphone treatment suitable for wide use in such countries as Nigeria.

In the sixth annual report of the Committee for Colonial Agricultural, Animal Health and Forestry Research reference is made to the work under the East African Agriculture and Forestry Research Organization with systemic insecticides against rosette disease of groundnuts. Although initial infection was not prevented, the aphids carrying the virus were killed. Work on the sudden-death disease of clove trees has shown that the disease is due to more than one cause and in young clove trees is largely caused by a new and undescribed species of 
Cryptosporella, which is also responsible for a high proportion of dieback in mature trees. Besides research on animal trypanosomiasis and particularly on 'Antrycide', research has been carried out on lapinized rinderpest virus. At the West African Cacao Research Institute, Tafo, investigations are proceeding into the diseases and pests of cacao, the agronomy of the crop, the breeding of improved types and problems of cocoa fermentation. At Rothamsted a survey of the occurrence of aluminium in the plant kingdom, including every family of flowering plant and vascular cryptogams, has shown that very strong accumulators of this element are confined to twenty, and moderately strong accumulators to twenty-eight, families.

Fuller space is given in this report to the work being undertaken by the Colonial Departments of Agriculture, Forestry and Veterinary Services, among which may be mentioned the investigations in British Guiana into the causes of loss in fertility of the 'pegasse' soils of the north-west, the study in the Gold Coast on the dieback disease of lime, and plantbreeding work in Kenya with wheat, maize, sorghum, barley and oats to produce disease-proof varieties of improved yield and commercial qualities, and in Tanganyika on coffee. The survey and collection of varieties of paddy have continued in Malaya, and the discovery in New Guinea of a tachinid parasite of the banana scab moth, Nacoleia octasema Meyr., offers the possibility of a biological method of controlling this pest. In Jamaica further work has been carried out on tick dip-fluids for cattle; besides cattlemanagement studies in Uganda, extensive field trials have been made of a copper preparation for seed disinfestation, and these have given promising results in the control of blackarm disease of cotton. Reports from the standing Sub-Committees for Cocoa Research, Soils and Stored Products Research are also included.

The fourth annual report of the Colonial Insecticides, Fungicides and Herbicides Committee, to which is appended an outline of the work of the Committee during 1947-50, emphasizes the high standard of the work of the Colonial Insecticides Research Team at Porton. The studies on aqueous suspensions of DDT particles in different size-ranges have yielded results which are important for the control of other insect pests besides adult mosquitoes, with which. the work has already been done. An inverse relation has been established between particle size of insecticides and their initial contact-toxicity to mosquitoes and a similar relation between particle size and fumigant effect, and the work has been extended to include its effect on the persistence of volatile insecticides with the view of determining formulations giving the maximum initial and residual toxicity. Besides the sorption of solid insecticides by dried mud-blocks, a study has been made of the contact-toxicity to mosquitoes of deposits from aqueous suspensions of inert dusts impregnated with insecticides from other solutions. Promising results have been obtained in the incorporation of insect. icides in resin surface coatings, and one containing 20 per cent DDT prevented for several months the fouling by barnacles of marine underwater wooden surfaces. At Silwood Park a detailed study was being made of the structure of insects to determine the mode of action of residual deposits, and also of the way in which insecticide particles are picked up by insects when moving over treated surfaces, while studies at Rothamsted have shown that at $110^{\circ} \mathrm{F}$.
DDT is rapidly lost by volatilization from crystalline deposits and that the presence of wax has little effect on the contact-toxicity of the glass plates. Final assessment of the results of the trials on the application of insecticides by aircraft against the tsetse fly is not yet possible, but under certain conditions and against certain species almost complete elimination of the tsetse population of a given area appears possible, although whether the method is economically feasible has yet to be proved. It has been necessary to abandon for the time being the project for establishing a West African Insecticide Research Unit. Final results on the treatment of African huts at Kasanje and Mbale, East Africa, for control of mosquitoes and malaria indicate that BHC applied at three-monthly intervals is the best insecticide to use.

The Colonial Economic Research Committee records in its fourth annual report that the study of the national income of Nigeria was initiated in the autumn of 1950 , and a survey of the available data relating to Colonial dependence on imported foods has been completed. Arrangements were made in March 1951 for a pilot investigation of the value of sample market surveys as an aid to the promotion of industrial development in the Colonial territories. It is hoped to recruit suitable economists to undertake studies of the retail trade in Tanganyika, Nyasaland and Zanzibar and of capital investment in the Colonial territories generally.

The report of the Tsetse Fly and Trypanosomiasis Research Committee for $1950-51$ is prefaced with some notes on the origin and past activities of the Committee. Its work on insecticides has now been taken over by the Colonial Insecticides, Fungicides and Herbicides Committee; and, when the Committee was reconstituted in 1949 and the directors of the East African Tsetse and Trypanosomiasis Research and Reclamation Organization and of the West African Institute for Trypanosomiasis Research were invited to join, the terms of reference were slightly amended and made to read as follows : "To consider and advise on the co-ordination of action, including research and reclamation, directed against human and animal trypanosomiasis".

Considerable progress has been made in studying the relation of the tsetse to its environment, and new techniques were being developed. Plans were being formulated for three schemes of experimental practical reclamation work, one in each of the East African Territories, and interesting results have been obtained in conjunction with the East African Veterinary Research Organization, with a programme of monthly and two-monthly prophylactic injections of 'Antrycide'. Close interest has been taken in the antimonial and arsenical compounds discovered by Dr. F. A. Friedheim for use in human trypanosomiasis, and, following satisfactory results with melarsen, further trials will be carried out.

The Colonial Fisheries Advisory Committee's report on Fisheries Research for $1950-51$ refers to the almost complete lack of trained and experienced research workers which has delayed implementation of the research programme. A good supply of candidates for fisheries research studentships to be awarded in 1951 became available, however, and from 1952 the staff situation should be easing. At the Inter-territorial Fisheries Research Station at Jinja, on Lake Victoria, an intensive study of the growth of the phytoplankton has been started as well as of the identification and life-histories of snails and of 
their parasites, and on growth-rates and breeding of several species of fish. Research at the West African Fisheries Research Institute was about to begin.

The report of the Director of the Anti-Locust Research Centre on locust research and control for 1950-51 reviews the advisory activities of the Centre, which are chiefly connected with regional anti-locust organizations, as well as that of the Desert Locust Control Executive Committee, and with the research being carried out on the taxonomy of locusts and grasshoppers, field investigations on the behaviour of adult desert locusts and on methods of control. Extra-mural researches mostly fall in four overlapping groups: three of them, namely, those investigations in biochemistry, physiology or behaviour which relate to phase phenomena, phenomena migration or to population dynamics, are only just beginning; the fourth group relates to the destruction of locusts by insecticides and machinery. A 20 per cent solution of dinitro-o-cresol has proved very effective for aircraft work, but baiting remains the principal method of control.

\section{TECHNIQUE OF ELECTRON MICROSCOPY \\ CONFERENCE AT ST. ANDREWS}

$\mathrm{T}$

HE Electron Microscopy Group of the Institute of Physics held a conference in St. Andrews University during June 19-21, which was attended by about eighty scientific workers. On the first day three symposia were held: recent experiences in the cutting of thin sections; critical testing of instrument performance; and replica techniques. This was followed by a few short original papers. The second day was entirely devoted to the reading and discussion of papers.

M. S. C. birbeck opened the session on section cutting by discussing modifications to be made in histological technique in order to cut sections thin enough for electron microscopy. Embedding and fixation were particularly dealt with, as it is in these preparative processes that the main difficulties now lie; the actual cutting of suitably prepared blocks is no longer a matter of special difficulty. The modified Cambridge rocking microtome will cut to $0.2 \mu$, and some Continental makers are producing instruments to cut even thinner sections than this.

It is desirable to embed the tissues in a harder medium than usual, and Mr. Birbeck favours 'ester wax', though Dr. C. E. Challice prefers the purer diethylene glycol distearate, and Prof. L. H. Bretschneider uses a wax mixture including carnauba wax. Fixatives which are suitable for optical preparations may fail for electron microscopy because they precipitate the protein in a fine form which shows spurious structure in the electron microscope size-range. There are exceptions, however, and the most successful fixatives for this purpose are those based on osmic acid and potassium dichromate. A tmann's mixture is specially recommended.

Dr. C. E. Challice opened the discussion and was in general agreement with Mr. Birbeck's methods, differing principally in the knife-blade he uses and in methods of removing the ester wax from the section when cut. Birbeck sublimes the wax in the electron beam itself, but Challice finds that this leaves a 'fixed' residue and prefers to warm the specimen in vacuo before exposing it to the beam.

Dr. J. Nuttings's paper opening the session on replica techniques was read for him by Dr. A. F. Brown. After ten years of development, the electron microscope is beginning to give results of real value to metallurgists; and this is happening, not because of special advances in technique and resolving power, but because of the accumulation of experience and data from the use of plastic replica techniques at moderate resolving power and magnification.

Comparison of dry-stripped 'Formvar' replicas with optical micrograms of the identical areas of the surface (made possible by a method developed by E. D. Hyam) show that at least in the optically resolvable range these replicas are completely reliable. Dr. G. L. J. Bailey, in discussion of this paper, expressed the opinion that the biggest problem before the electron microscopist in the metallurgical field is to persuade the classical metallurgist to accept his results; but he was able to cite instances where the electron microscope has proved trustworthy when the conventional optical methods have given misleading results.

Replica methods giving higher resolving power than the simple plastic replica are available or are being developed, but cannot compete with the speed and ease of the dry-stripped 'Formvar' process. Such are the method of polymerizing a monomer in situ to form an intermediate cast (in a two-stage process), and, as J. B. Le Poole mentioned, the use of an evaporated silver intermediate cast with silicon monoxide for the final replica, which is said to have a grain size of atomic dimensions and give maximum resolution. The resolution of the simple plastic replica, also, can be improved by preshadowing the metal surface; but there is sometimes difficulty in stripping the shadowing metal, and the discussion showed that the conditions under which this occurs are not understood. A paper by A. W. Agar and R. S. M. Revell, read later in the conference, discussed plastic replicas of ferrous specimens, and suggested that; though the major features are reliably pictured, some fine detail, especially on ferrite grains, is probably spurious and due to the etching process.

The basis of interpretation of replicas of some chromium-nickel steels was broadened by Dr. J. F. Brown and D. Clark, who isolated particles of sigma-phase electrolytically and investigated their crystal structure by electron diffraction (of individual particles selected from the electron microscope field). Correlation of the particle shapes with features of the replicas was possible. J. I'rotter has observed two intermediate nitride phases in alpha-iron in addition to the well-known $\mathrm{Fe}_{4} \mathrm{~N}$.

The interesting work of Drs. I. M. Dawson and V. Vand on spiral growth of crystal faces, particularly of the paraffin $n$-hexatriacontane (see Nature, 167, 476 ; 1951) was reported to the meeting, and one or two points of general interest to electron microscopists emerged. Gold-manganin is mobile in the electron beam on a paraffin surface and therefore cannot be used as a shadowing metal; palladium is satisfactory for this purpose. The graphitization of the paraffin in the beam is not instantaneous, and paraffin electron-diffraction patterns can be observed for about five minutes before they degenerate into diffuse rings. There was some discussion on the stability of these materials in the beam, and it seems that chemical structure is at least as important as 